\title{
Innovative analysis of HS 6-5-2 drills edges quality
}

\author{
Raluca Daicu ${ }^{1, *}$, Valentin Dițu ${ }^{1}$ \\ ${ }^{1}$ Transilvania University of Braşov, Department of Manufacturing Engineering, Mihai Viteazu No.5, \\ Braşov, Romania
}

\begin{abstract}
The paper is analyzing the quality of $\varnothing 8$ drills edges from HS 6-5-2 steel, using an innovative technique, the measurement of electrical current at cutting. The method is useful to take the right decision about drills acquisition from different suppliers based on the quality/price ratio. Also, it can be made a fast quality comparison of drills that leads to a selection of the acquisition places. The analysis of a drill batch is done using the microscope and the measurement of the electrical current at cutting, showing the better accuracy of the last method.
\end{abstract}

\section{Introduction}

The estimation of the cutting tool edge wear and tool life is high due to large scale using of the numerical command machines and the manufacturing flexible lines, and these need to estimate the moment when the cutting tool has to be changed.

Another important direction about the estimation of cutting tool edge life is the quality control of the cutting edge in the series production, or when acquisitioning a batch of tools by a beneficiary, or at the comparison of different cutting tools from different producers to study the quality/price ratio and decide from where is profitable to buy the cutting tools that an industrial enterprise needs.

The methods used until now to estimate the cutting edge wear and tool life need many experiments, great material and time consumption and are expensive. Thus, it is necessary to find a method that does not have the disadvantages of the present methods.

It is known the fact that when cutting a metal with an edge of a good electrical conducting material (high speed steel, metallic carbide, etc.) it appears an electrical current as consequence of the next physical effects and phenomenon: the Seebeck effect, the Thomson effect, the phenomenon of emission in metals [1-10]. Because these physical effects and phenomenon are generally based on the heat generation in the cutting process, and the wear of the cutting tool clearly depends on it, results that the measurement of the electrical current at cutting leads to a good appreciation of the cutting tool wear state.

In paper [1] is shown the fact that at turning S275JR steel with two SPMR 150612-P30 cutting inserts, in the same conditions, there were obtained different values for the initial voltage of the electrical current at cutting, so, for the first insert it was obtained $U=12.3$ $\mathrm{mV}$ and for the second insert $\mathrm{U}=13 \mathrm{mV}$. If different values for the voltage of electrical

\footnotetext{
*Corresponding author: raluca.daicu@unitbv.ro
} 
current at cutting were obtained results that in the cutting zone there are different temperatures. This can be explained by the fact that the value of the electrical current at cutting is higher due to the imperfections on the cutting edge. Normally, this type of edge should be wear out faster, so it should have a shorter life. To verify this hypothesis there were made tries at wear, on S275JR steel, for the next cutting parameters: $\mathrm{s}=91.1 \mathrm{~m} / \mathrm{min}$, $\mathrm{f}=0.302 \mathrm{~mm} / \mathrm{rev}, \mathrm{a}=2 \mathrm{~mm}$. The $\mathrm{S} 275 \mathrm{JR}$ steel has the next chemical composition: $\mathrm{C}=$ $0.22 \%, \mathrm{Mn}=1.15 \%, \mathrm{P}=0.055 \%, \mathrm{~S}=0.055 \%$, and the tensile strength is $440 \mathrm{Mpa}$ (44 $\mathrm{daN} / \mathrm{mm}^{2}$ ). The obtained results are graphically shown in figure 1.

If the admissible wear is $\mathrm{VB}_{\mathrm{B} \text { adm. }}=0.4 \mathrm{~mm}$ the next tool life values were obtained: $\mathrm{T}_{\mathrm{I}}=12.06 \mathrm{~min} ; \mathrm{T}_{\mathrm{II}}=8.55 \mathrm{~min}$.

Taking as base the tool life of the cutting insert with $\mathrm{U}=12.3 \mathrm{mV}$ it can be observed a decreasing of the tool life for the cutting insert with $U=13 \mathrm{mV}$ of $29 \%$.

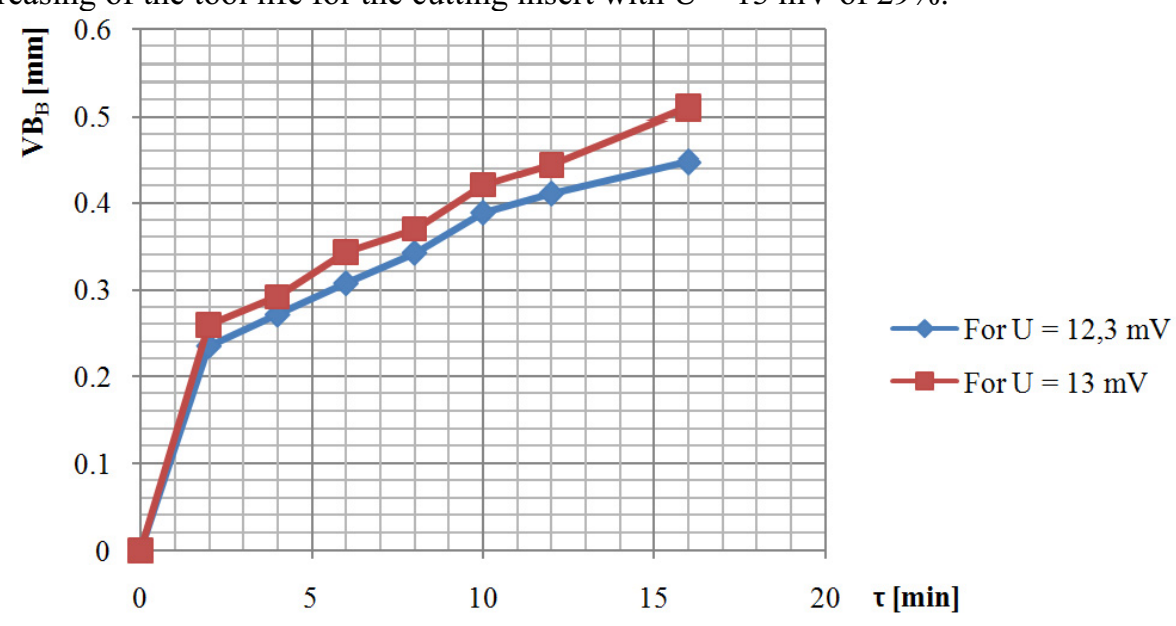

Fig. 1. Graphics for tries at wear (after [1]).

Also in paper [1] is shown the connection between electrical current at cutting and wear of cutting edge at turning 1C45 steel with a SPMR 150612 - P30 metallic carbide insert, with geometry $\alpha=5^{0} ; \gamma=6^{0} ; \chi=45^{0}$ resulting the relation 1 .

$$
V B_{B}=112.41061 * s^{0.946447 *}\left(U-3.567 * s^{0.306} * f^{0.117} * a^{0.097}\right) \quad[\mathrm{mm}]
$$

where,

$\mathrm{VB}_{\mathrm{B}}[\mathrm{mm}]$ - wear on the side surface;

$\mathrm{s}[\mathrm{m} / \mathrm{min}]$ - cutting speed;

$\mathrm{f}[\mathrm{mm} / \mathrm{rev}]$ - cutting feed;

a [mm] - cutting depth;

$\mathrm{U}[\mathrm{mV}]$ - voltage of the cutting electrical current.

The $1 \mathrm{C} 45$ steel has the next chemical composition: $\mathrm{C}=0.45 \%, \mathrm{Si}=0.4 \%, \mathrm{Mn}=0.5 \%$, $\mathrm{P}=0.045 \%, \mathrm{~S}=0.045 \%, \mathrm{Cr}=0.4 \%, \mathrm{Mo}=0.1 \%, \mathrm{Ni}=0.4 \%$, and the tensile strength is 660 $\mathrm{Mpa}(66 \mathrm{daN} / \mathrm{mm} 2)$.

In the same paper it is shown the connection between the tool life of the cutting edge and the cutting electrical current at turning the $\mathrm{AlCu} 4 \mathrm{MgTi}$ aluminum alloy heat treated, with an edge from HS 18-1-1-5 steel and another edge from metallic carbide K10. The obtained relations are (2) and (3). 


$$
\begin{array}{ll}
T=\frac{101}{s^{0.745} \cdot f^{0.96} \cdot a^{0.2} \cdot U} & {[\mathrm{~min}]} \\
T=\frac{511.3}{s^{0.85} \cdot f^{0.39} \cdot a^{0.12} \cdot U} & {[\mathrm{~min}]}
\end{array}
$$

where, T [min] - tool life.

The presented information show the fact that with the measurement of the electrical current at cutting it can be diagnosed the wear state of a cutting edge and also the fact that the specialty literature was focused more on the turning process and less on other processes like drilling.

\section{The analysis of the connection between the value of the electrical current at drilling and the quality of the cutting edge}

The initial quality of a cutting edge, as shown in section 1, can be appreciated by the value of the voltage of initial electrical current at cutting. The higher the voltage is, the higher the temperature is, due to the imperfections of the cutting edge. In this section is analyzed the connection between the initial imperfections of the drill's edge and the initial value of the cutting electrical current voltage.

There were purchased 30 drills with $\Phi 8 \mathrm{~mm}$ diameter, the material of the cutting edge being HS 6-5-2 steel. For shortening the necessary time for experiments, the drilling was done on the $41 \mathrm{MoC} 11$ steel (tensile strength - $950 \mathrm{MPa}$ ), with the drilling machine 6GCODA1. The electrical current at cutting was measured with the installation from figure 2.

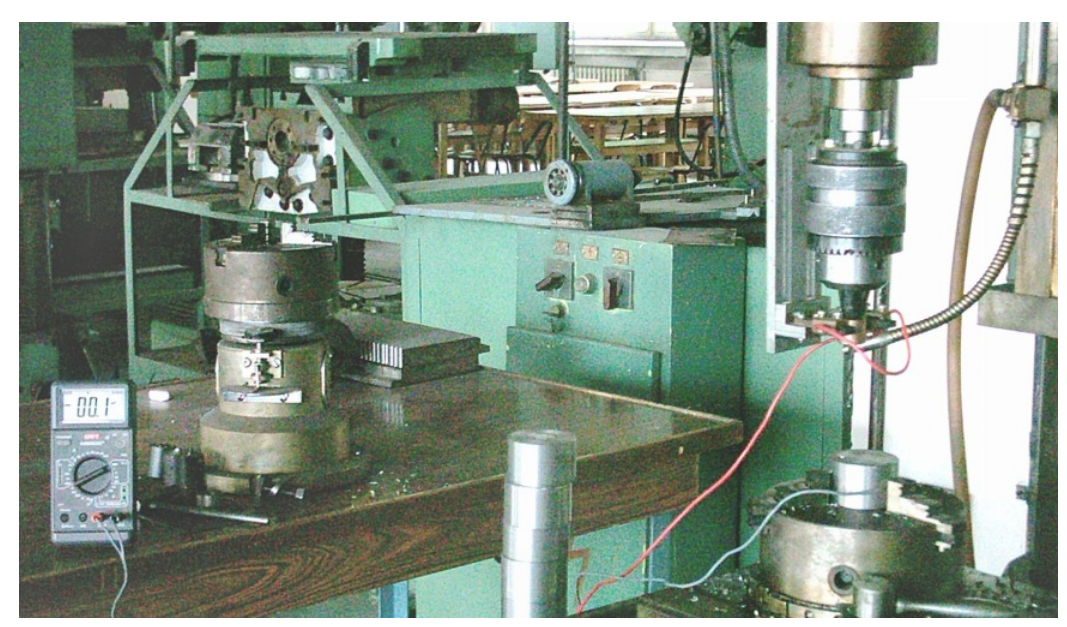

Fig. 2. Experimental setup for measuring the electrical current at drilling. 
In table 1 are centralized the results obtained for initial electrical current at cutting, for all the 30 drills.

Table 1. Obtained values for initial electrical current voltage at drilling $41 \mathrm{MoC} 11$ steel.

\begin{tabular}{|c|c|c|c|c|}
\hline No. of drill & $\begin{array}{c}\text { Drill } \\
\text { diameter } \\
{[\mathrm{mm}]}\end{array}$ & $\begin{array}{c}\text { Spindle } \\
\text { speed } \\
\text { [rev/min] }\end{array}$ & $\begin{array}{c}\text { Feed } \\
{[\mathrm{mm} / \mathrm{rev}]}\end{array}$ & $\begin{array}{l}\text { Voltage "Uo" of } \\
\text { electrical current at } \\
\text { cutting }[\mathrm{mV}]\end{array}$ \\
\hline 1 & \multirow[t]{30}{*}{1} & \multirow{30}{*}{560} & \multirow{30}{*}{0.25} & 0.5 \\
\hline 2 & & & & 0.5 \\
\hline 3 & & & & 0.4 \\
\hline 4 & & & & 0.3 \\
\hline 5 & & & & 0.3 \\
\hline 6 & & & & 0.6 \\
\hline 7 & & & & 0.2 \\
\hline 8 & & & & 0.3 \\
\hline 9 & & & & 0.4 \\
\hline 10 & & & & 0.2 \\
\hline 11 & & & & 0.4 \\
\hline 12 & & & & 0.4 \\
\hline 13 & & & & 0.5 \\
\hline 14 & & & & 0.6 \\
\hline 15 & & & & 0.6 \\
\hline 16 & & & & 0.5 \\
\hline 17 & & & & 0.3 \\
\hline 18 & & & & 0.2 \\
\hline 19 & & & & 0.2 \\
\hline 20 & & & & 0.6 \\
\hline 21 & & & & 0.4 \\
\hline 22 & & & & 0.4 \\
\hline 23 & & & & 0.6 \\
\hline 24 & & & & 0.8 \\
\hline 25 & & & & 0.4 \\
\hline 26 & & & & 0.7 \\
\hline 27 & & & & 0.6 \\
\hline 28 & & & & 0.6 \\
\hline 29 & & & & 0.5 \\
\hline 30 & & & & 0.6 \\
\hline
\end{tabular}

Using the microscope there were examined the edges of each drill in order to find manufacturing defects and to explain the value of the cutting electrical current voltage.

For a drill there were visualized the cutting lips and the chisel edge identifying if they have defects or not.

The sequence of the experiments steps was the next: microscope visualization - take decision about drill quality - measuring the electrical current at drilling - take decision about drill quality based on the voltage value of the electrical current at cutting.

The drills were grouped in 3 categories :

- Drills quality I : $\mathrm{U}_{0}=0.1 \div 0.3 \mathrm{mV}-7$ pieces

- Drills quality II : $\mathrm{U}_{0}=0.4 \div 0.5 \mathrm{mV}-13$ pieces

- Drills quality III : $\mathrm{U}_{0}=0.6 \div 0.8 \mathrm{mV}-10$ pieces 
In figure 3 are images of the two cutting lips and the chisel edge for drill no. 10 that had the voltage of the electrical current at cutting of $\mathrm{U}_{0,10}=0.2 \mathrm{mV}$ (drill quality $\mathrm{I}$ ).
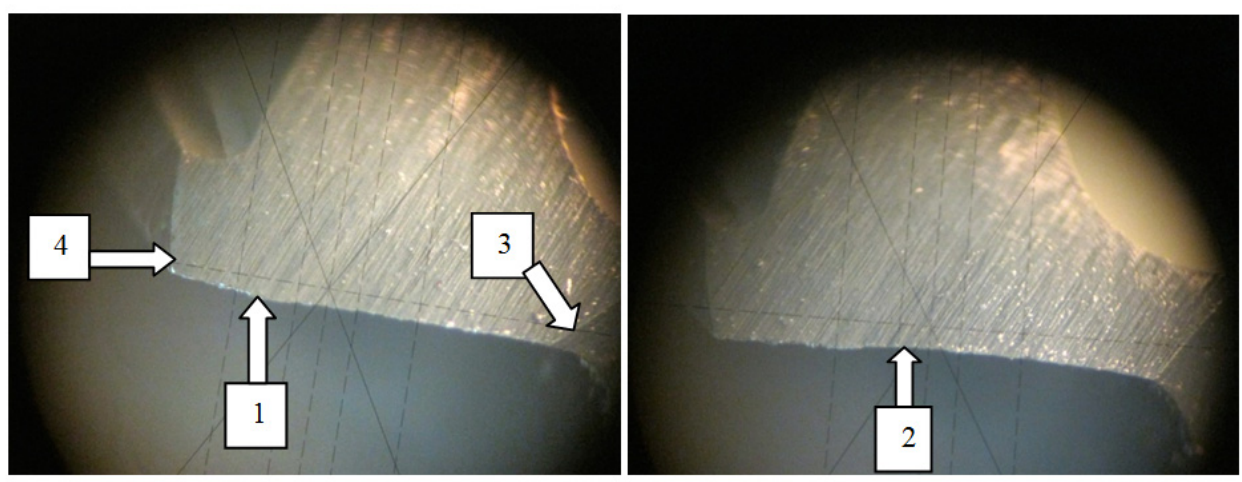

Fig. 3. Cutting lips (1, 2), chisel edge (3) and corner (4) for drill no.10 from table 1.

From figure 3 it can be seen the fact that the cutting lips and the chisel edge are adequate from the shape and roughness point of view. Also it can be seen that the corners of the drill are very good. All drills should look like this one.

In figure 4 are images of the two cutting lips and the chisel edge for drill no. 29 that had the cutting electrical current voltage of $\mathrm{U}_{0,29}=0.5 \mathrm{mV}$ (drill quality II).
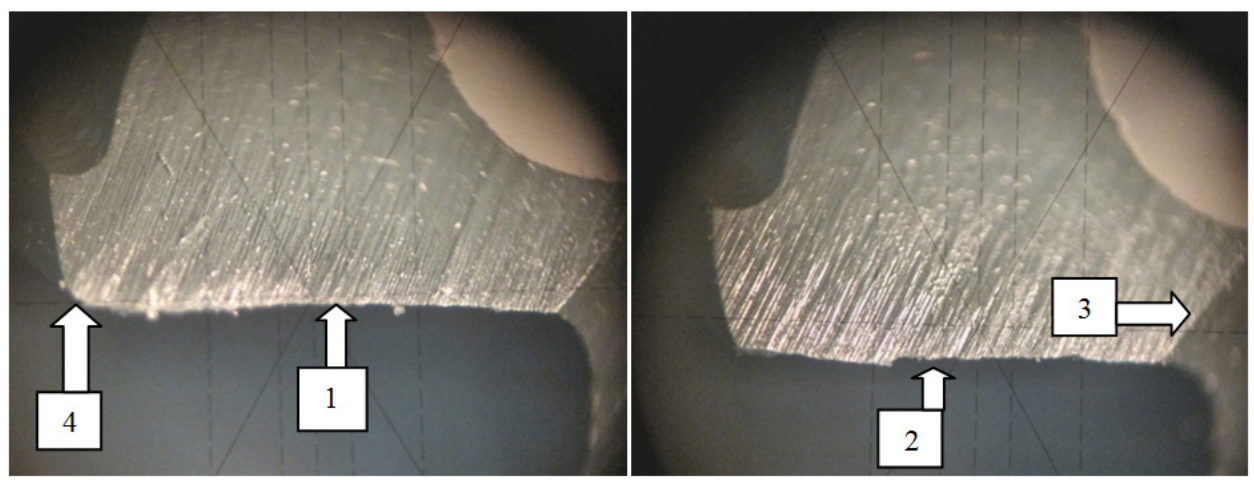

Fig. 4. Cutting lips (1, 2), chisel edge (3) and corners (4) for drill no.29 from table 1.

Analyzing the images from figure 4 it can be seen that the chisel edge (2) is very good sharpened, the drill corners (4) are one good and one rounded, fact that leads to an increase of the temperature in the cutting zone, that also leads to the increase of the electrical current at cutting, and the sharpening of the cutting lips $(1,2)$ is not perfectly done. All these observations explain why the voltage of electrical current at cutting has a higher value than the drill no. 10 presented in figure 3.

In figure 5 are presented images of cutting edges from drill no. 14 that had an initial electrical current of $\mathrm{U}_{0,14}=0.6 \mathrm{mV}$. 

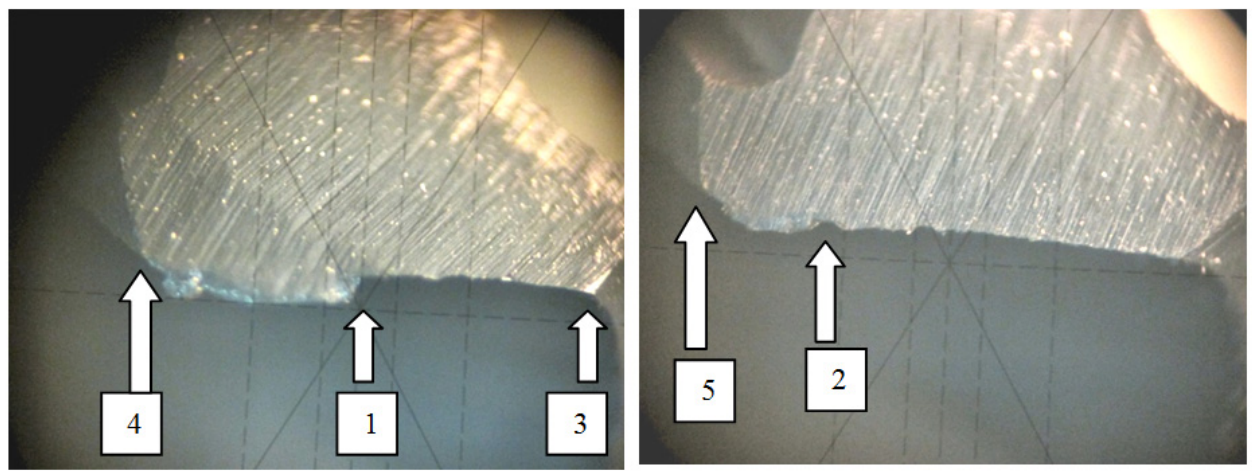

Fig. 5. Cutting lips (1, 2), chisel edge (3) and corners $(4,5)$ for drill no.14 from table 1.

Analyzing the images from figure 5 it can be seen that the chisel edge (3) is partially good sharpened, the cutting lips $(1,2)$ and corners $(4,5)$ are improper, fact that explains the increasing temperature in the cutting zone and also of the cutting electrical current voltage.

In figure no. 6 are shown microscope images of drill no. 11 that had a voltage of the electrical current at cutting of $\mathrm{U}_{0,11}=0.4 \mathrm{mV}$.

It can be seen an interesting thing, the fact that at sharpening it was used an abrasive wheel with coarse-grained and the roughness of the land surfaces clearly increased.
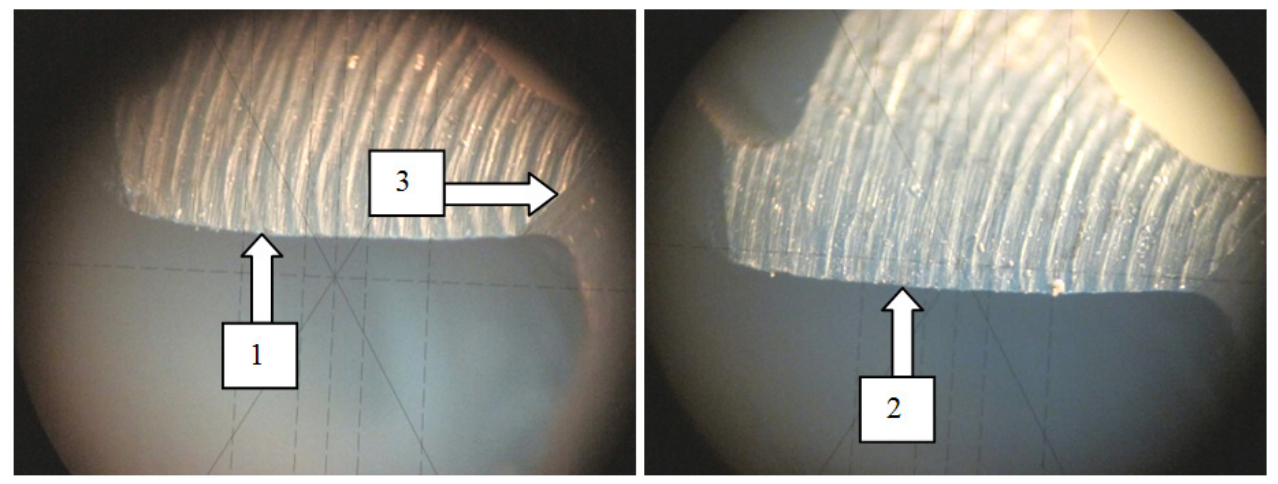

Fig. 6. Cutting lips $(1,2)$ and chisel edge (3) for drill no.11 from table 1.

Even if it can be seen that the sharpening was done properly, the voltage of the electrical current increased so the drill was not in the quality I group, but in the quality II group.

\section{Conclusions}

Due to the experiments, the next conclusions can be drawn:

- The appearance of the electrical current at cutting is known since 1950 [2], but it's utilization in practical applications was recently developed;

- The electrical current at cutting is an innovative method for the quality appreciation of the drills edges and it can be easily used;

- From the analyzed drills batch, $23.33 \%$ are quality I, $43.33 \%$ quality II and

$33.34 \%$ quality III; in this situation the drills batch has a satisfying quality; 
- If the drills are analyzed only at microscope it can be made an error in the appreciation of the drill batch quality of $14 \%$;

- The electrical current at cutting is sensible to any imperfection of the drill edge;

- The electrical current at cutting has shown an improper roughness obtained at sharpening due to coarse-grain of the used abrasive wheel;

- If the life of the drills from each quality group is determined, than it can be made an analysis of the quality/price ratio.

\section{References}

1. V. Diţu, AJME 1, 63 (2008)

2. R. Daicu, G. Oancea, AMM 808, 40 (2015)

3. H. Bagchi, S.K. Basu, Wear 26, 39 (1973)

4. V. Diţu, WSEAS 2, 322 (2009)

5. A.L. Plotnikov, E.G. Krylov, E.M. Frolov STIN 1, 2 (2009)

6. M. Murata, S. Kurokawa, O. Ohnishi, CSME 79, 2546 (2013)

7. M. Murata, S. Kurokawa, O. Ohnishi, M. Uneda, T. Doi, CSME 6, 958 (2012)

8. H. Hirota, M. Murata, A. Kojima, K. Yanagihara, JSPE 64, 1191 (1998)

9. V. Diţu, AJME 8, 18 (2010)

10. R. Tanaka, A. Hosokawa, K. Yamada, T. Ueda, Proceedings of the Seventh International Conference on Progress of Machining Technology, 786 (2004) 